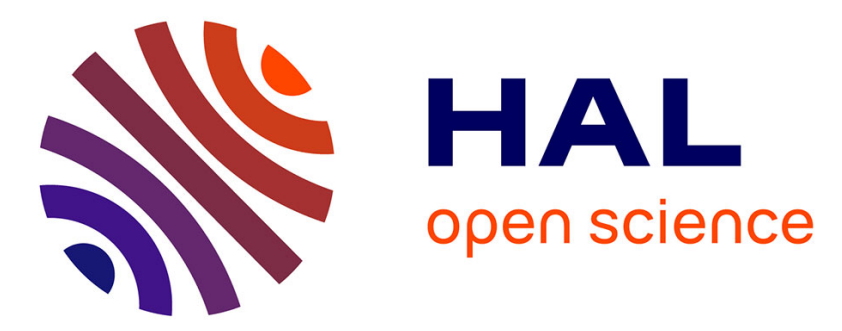

\title{
Experimental Comparisons Between Implicit and Explicit Implementations of Discrete-Time Sliding Mode Controllers: Toward Input and Output Chattering Suppression
}

Bin Wang, Bernard Brogliato, Vincent Acary, Ahcene Boubakir, Franck

Plestan

\section{To cite this version:}

Bin Wang, Bernard Brogliato, Vincent Acary, Ahcene Boubakir, Franck Plestan. Experimental Comparisons Between Implicit and Explicit Implementations of Discrete-Time Sliding Mode Controllers: Toward Input and Output Chattering Suppression. IEEE Transactions on Control Systems Technology, 2015, 23 (5), pp.2071-2075. 10.1109/TCST.2015.2396473 . hal-01625866

\section{HAL Id: hal-01625866 https://hal.science/hal-01625866}

Submitted on 29 Oct 2017

HAL is a multi-disciplinary open access archive for the deposit and dissemination of scientific research documents, whether they are published or not. The documents may come from teaching and research institutions in France or abroad, or from public or private research centers.
L'archive ouverte pluridisciplinaire HAL, est destinée au dépôt et à la diffusion de documents scientifiques de niveau recherche, publiés ou non, émanant des établissements d'enseignement et de recherche français ou étrangers, des laboratoires publics ou privés. 


\title{
Experimental Comparisons Between Implicit and Explicit Implementations of Discrete-Time Sliding Mode Controllers: Toward Input and Output Chattering Suppression
}

\author{
Bin Wang, Bernard Brogliato, Vincent Acary, Ahcene Boubakir, and Franck Plestan
}

\begin{abstract}
This brief presents a set of experimental results concerning the sliding mode control of an electropneumatic system. Two discrete-time control strategies are considered: an explicit and an implicit (that is very easy to implement with a projection on the interval $[-1,1])$ Euler discretizations. While the explicit implementation is known to generate numerical chattering, the implicit one is expected to significantly reduce chattering while keeping the accuracy. The experimental results reported in this brief remarkably confirm that the implicit discrete-time sliding mode supersedes the explicit ones, with several important features: chattering in the control input is almost eliminated (while the explicit and saturated controllers behave like high-frequency bang-bang inputs), the input magnitude depends only on the perturbation size and is independent of the controller gain and sampling time.
\end{abstract}

Index Terms-Chattering, discrete time, experiment, robust control, set-valued controller, sliding mode.

\section{INTRODUCTION}

$\mathbf{S}$ LIDING-MODE control has very attractive features like robustness and simplicity of implementation, with few gains to tune [10], [14], [15]. Its main drawback is the existence of the so-called chattering phenomenon, which may be due to actuators limitations, unmodelled dynamics, or time discretization. The implementation of sliding-mode controllers in discrete time has been the object of many studies [3], [13]. Several works recently focused on the time-discretization effects, showing that an explicit implementation of either the Euler of Zero-Order-Hold discretizations yields limit cycles [5], [6], while the implicit form suppresses, in theory, the numerical chattering [1], [2] due to the time discretization. What is meant by explicit and implicit discrete-time sliding mode controllers will be recalled in the sequel. The analysis

This work was supported by the French National Research Agency through the ChaSliM Project under Grant ANR 2011 BS03 00701. Recommended by Associate Editor E. Usai.

B. Wang, B. Brogliato, and V. Acary are with the Institut National de Recherche en Informatique et Automatique, Grenoble 38330, France (e-mail: bin.wang@inria.fr; bernard.brogliato@inria.fr; vincent.acary@ inria.fr).

A. Boubakir was with the Institut de Recherche en Communications et Cybernétique de Nantes, Ecole Centrale de Nantes, Nantes 44300, France. He is now with the Laboratoire de Commande des Processus, Ecole Nationale Polytechnique d'Alger, Algiers 16051, Algeria (e-mail: ah_boubakir@yahoo.fr).

F. Plestan is with the Institut de Recherche en Communications et Cybernétique de Nantes, Ecole Centrale de Nantes, Nantes 44300, France (e-mail: franck.plestan@irccyn.ec-nantes.fr). and simulations in [1] and [2] show that the implicit controller has the same features as its continuous-time counterpart. We may summarize them as follows.

1) When there is no perturbation, the sliding surface is reached after a finite number of steps.

2) When a perturbation acts on the system, the state of the nominal system reaches the sliding surface after a finite number of steps, while the perturbation effect is attenuated by a factor $h$ on the system state.

3) The controller magnitude is independent, in the sliding mode, of the controller gain, and there is no need to adapt the gain (denoted as $G$ in the sequel) online.

4) Theoretically, there is no numerical chattering during the sliding mode, neither in the sliding variable nor in the input.

5) The discrete-time controller keeps the simplicity of its continuous-time counterpart, with no added gain to tune.

6) Computing the input at each step boils down to solving a simple generalized equation, equivalently a projection on $[-1,1]$, or solving a quadratic program. This is quite easy to implement in a code.

The implicit algorithm extends to higher dimension systems and with sliding surfaces of codimension $\geqslant 2$ [2]. The main objective of this brief is to confirm these features experimentally.

This brief is organized as follows. In Section II, the dynamics and the various controllers of the electropneumatic actuators are presented. Section III is dedicated to the experimental results: the explicit and the implicit discrete-time algorithms are applied to the system and compared in terms of their overall performance, comprising the tracking accuracy, the input chattering, the input magnitude, and the disturbance rejection, when the controller gain and the sampling period are varied. The saturated explicit controller has also been tested, and the results may be found in [17]. The conclusion ends this brief in Section IV.

\section{Dynamics of the Plant And Controllers}

\section{A. Implicit Controller Implementation}

Let us explain how the so-called implicit controller (which might be also named the projected sliding-mode controller) is calculated in case of tracking of a reference output. We consider a scalar system $\dot{x}(t)=u+d(t), d(t) \leqslant \delta<1$ for some known $\delta$. Let the sliding variable be $\sigma=x-x_{d}$. The controller is set to $u(x, t) \in-\operatorname{sgn}(\sigma)+\dot{x}_{d}(t)$ so that the closed-loop system is $\dot{\sigma}(t) \in-\operatorname{sgn}(\sigma(t))+d(t)$. 


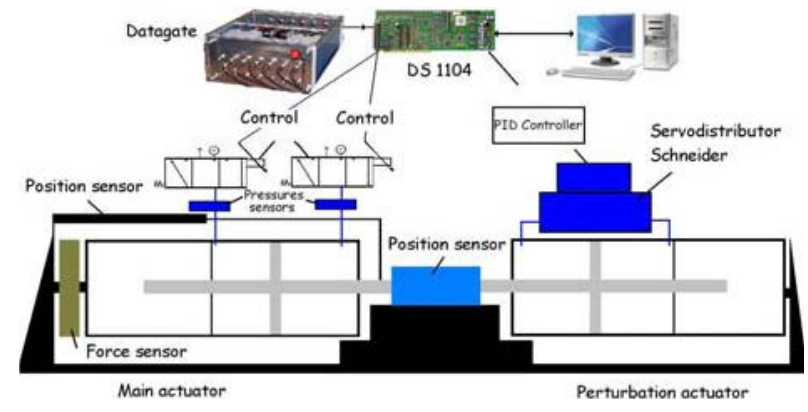

Fig. 1. Scheme of the electropneumatic system [12].

The plant discretization is given as $x_{k+1}-x_{k} / h=u_{k}+d_{k}$. Since the disturbance is unknown, the discrete-time controller is calculated from a nominal system as

$$
\left\{\begin{array}{l}
\tilde{\sigma}_{k+1}=\sigma_{k}+h u_{k}-x_{d, k+1}+x_{d, k} \\
u_{k} \in-\operatorname{sgn}\left(\tilde{\sigma}_{k+1}\right)+\frac{x_{d, k+1}-x_{d, k}}{h}
\end{array}\right.
$$

where $\tilde{\sigma}_{k}$ is to be seen as the nominal model state or just an intermediate variable (equal to $\sigma_{k}$ if $d(t)=0)$. From (1), one infers the generalized equation $\tilde{\sigma}_{k+1}-\sigma_{k} \in-h \operatorname{sgn}\left(\tilde{\sigma}_{k+1}\right)$. After few manipulations, it follows that $\tilde{\sigma}_{k+1}-\sigma_{k}=-h \operatorname{proj}\left([-1,1] ;-\left(\sigma_{k} / h\right)\right)$. Using the first line of (1), it follows that the implicit controller is $u_{k}=\operatorname{proj}\left([-1,1] ;-\left(\sigma_{k} / h\right)\right)+\left(x_{d, k+1}-x_{d, k} / h\right)$. Recall that the explicit discretization of the controller reads as $u_{k}=-\operatorname{sgn}\left(\sigma_{k}\right)+\left(x_{d, k+1}-x_{d, k} / h\right)$. As recalled in the introduction, proved theoretically in [5], [6], and [16], and shown experimentally in this brief, it yields strong numerical chattering. When $\left|\sigma_{k}\right|<h \Leftrightarrow \tilde{\sigma}_{k+1}=0$, one obtains with the implicit input $\sigma_{k+1}=h d_{k}$ : the disturbance is attenuated by a factor $h$ in the vicinity of the sliding surface. See [1] and [2] for the analysis of the implicit controllers, which are also shown to guarantee convergence in a finite number of steps to the sliding surface $\tilde{\sigma}_{k}=0$.

\section{B. Plant Dynamics and Controllers}

The electropneumatic system used for the controllers evaluation consists of two actuators that are controlled by two servodistributors (Fig. 1). Each actuator is composed by two chambers denoted by $P$ (positive) and $N$ (negative). The controllers proposed in the sequel are designed to control the position of one of these two actuators, named main actuator, whereas the second actuator, named perturbation actuator and mechanically connected to the main one, is used to produce an external perturbation force. With a nominal seven-bar source pressure, the maximum produced force is $2720 \mathrm{~N}$; furthermore, both actuators have the same physical features: piston diameter is $80 \mathrm{~mm}$ and rod diameter $25 \mathrm{~mm}$. The external perturbation force controller is not under interest in this brief and has been designed and tuned by Sitia Corporation (France), which has built the experimental setup. The air mass flow rates $q_{m}$ entering in the chambers are modulated by two three-way servodistributors. The pneumatic jack horizontally moves a load carriage of mass $M$.
Under some assumptions detailed in [12], the dynamic model of the pneumatic actuator can be written as a nonlinear system that is affine in the control input $\left[u_{P} u_{N}\right]^{T}, u_{P}\left(\right.$ also $\left.u_{N}\right)$ being the control input of the servodistributor connected to the $P$ (also $N$ ) chamber. The model of the electropneumatic experimental setup reads as

$$
\left\{\begin{array}{l}
\dot{p}_{P}=\frac{k r T}{V_{P}(y)}\left[\varphi_{P}+\psi_{P} \cdot u_{P}-\frac{S}{r T} p_{P} v\right] \\
\dot{p}_{N}=\frac{k r T}{V_{N}(y)}\left[\varphi_{N}+\psi_{N} \cdot u_{N}+\frac{S}{r T} p_{N} v\right] \\
\dot{v}=\frac{1}{M}\left[S\left(p_{P}-p_{N}\right)-b_{v} v-F\right] \\
\dot{y}=v
\end{array}\right.
$$

with $p_{P}$ (resp. $p_{N}$ ) the pressure in the $P$ (resp. $N$ ) chamber, and $y$ and $v$ being the position and velocity of the actuator. The force $F$ is a disturbance that considers dry friction and unknown external forces. Note that the previous system appears to have two control inputs given that there is one servo distributor connected to each chamber. In the sequel, only the main actuator position is controlled: given that there is a single control objective, one states that $u=u_{P}=-u_{N}$. The constant $k$ is the polytropic constant, $r$ is the ideal gas constant, $T$ is the temperature that is supposed to be the same inside or outside the chambers, and $b_{v}$ is the viscous friction constant. $V_{P}$ and $V_{N}$ are the volumes in both chambers. These volumes depend on the actuator position $y . S$ is the piston section and is constant. Finally, $\varphi_{X}$ and $\psi_{X}(X$ being $P$ or $N)$ are both fifth-order polynomial functions versus $p_{X}$ [11] and allow one to model the mass flow rate $q_{X}$ in the chamber $X$ such that $q_{X}=\varphi_{X}\left(p_{X}\right)+\psi_{X}\left(p_{X}\right) u_{X}$. Equation (2) with a single input may be rewritten as $\dot{x}=\left(f_{n}+\Delta f\right)+\left(g_{n}+\Delta g\right) u$ with $f_{n}, g_{n}$ the nominal dynamics, and $\Delta f$ and $\Delta g$ the uncertainties and perturbations [7]. Let us define the so-called sliding variable as

$$
\sigma(x, t)=\ddot{e}+\lambda_{1} \dot{e}+\lambda_{0} e
$$

with $e=y-y_{d}(t), y_{d}(t)$ being the desired trajectory, supposed to be sufficiently differentiable. The coefficients $\lambda_{1}, \lambda_{0}$ are defined such that, given $z$ a complex variable, the polynomial $Q(z)=z^{2}+\lambda_{1} z+\lambda_{0}$ is Hurwitz. As shown in [7] and [9], the first-time derivative of $\sigma$ can be written as

$$
\dot{\sigma}=\Psi_{n}(x, t)+\Delta \Psi(t)+\left[\Phi_{n}(x)+\Delta \Phi(t)\right] u
$$

such that $\Psi_{n}$ and $\Phi_{n}$ are the nominal functions and $\Delta \Psi$ and $\Delta \Phi$ are the uncertain terms. One supposes that $\Delta \Phi$ is sufficiently small with respect to $\Phi_{n}$ to ensure that $1+\left(\Delta \Phi / \Phi_{n}\right)>0$. From a practical point of view, this assumption is not too strong: it simply means that the uncertainties are small compared with the nominal values. Let us consider the control law ${ }^{1}$

$$
u=\frac{1}{\Phi_{n}}\left[-\Psi_{n}+v\right] .
$$

\footnotetext{
${ }^{1}$ As shown in [4], such a control law allows one to reduce the magnitude of the sliding mode controller using the nominal informations in the controller.
} 
By applying (5) in (4), one gets

$$
\dot{\sigma}=\frac{\Delta \Phi}{\Phi_{n}} \Psi_{n}+\Delta \Psi+\left[1+\frac{\Delta \Phi}{\Phi_{n}}\right] v .
$$

The controller $v$ is a sliding-mode one defined as

$$
v \in-G \operatorname{sgn}(\sigma)
$$

with $G$ tuned sufficiently large to counteract the disturbances. The controller $v$ has been implemented under its discrete forms as follows (with $k \geqslant 0, \sigma_{k} \triangleq \sigma(k h), h$ being the sampling period).

1) Explicit sliding mode control (with $\operatorname{sgn}(\cdot)$ function)

$$
v_{k}=-G \operatorname{sgn}\left(\sigma_{k}\right) .
$$

2) Explicit saturated sliding mode control (with sat $(\cdot)$ function)

$$
v_{k}=-G \operatorname{sat}\left(\sigma_{k}, \epsilon\right)=-G\left\{\begin{array}{l}
\operatorname{sgn}\left(\sigma_{k}\right), \quad \text { if }\left|\sigma_{k}\right| \geqslant \epsilon \\
\sigma_{k}, \quad \text { if }\left|\sigma_{k}\right|<\epsilon .
\end{array}\right.
$$

3) Implicit sliding mode control (with $\operatorname{sgn}(\cdot)$ multifunction)

$$
v_{k} \in-G \operatorname{sgn}\left(\sigma_{k+1}\right)
$$

(implemented with a projection as indicated in Section II-A).

\section{EXPERIMENTAL RESULTS}

This section is devoted to analyze the experimental data. The controllers have been implemented with several feedback gains and sampling times. The length of the interval of study is $20 \mathrm{~s}$. The saturation input has been tested for six different values of the saturation width: the results were quite similar to those of the explicit controller. Thus, they are not reported here but can be found in [17], in which much more experimental data are reported. The comparisons are made mainly with respect to the inputs $u$ and $v$ being the magnitude and chattering, respectively, and the tracking error $e$.

\section{A. Comparison of the Tracking Errors $e$}

The data in Tables I and II characterize the position-tracking error $e$ obtained by the two different implementation methods, from the aspects of absolute value average $(<|e|>)$, range $[\operatorname{Rge}(e)]$, standard deviation $[\operatorname{SD}(e)]$, and variation with five different sampling periods. The variation of a real-valued function $f(\cdot)$ defined on an interval $[a, b] \subset R$ is the quantity

$$
\operatorname{Var}_{[a, b]}(f)=\sum_{i=0}^{N-1}\left|f\left(t_{i+1}\right)-f\left(t_{i}\right)\right|
$$

where the set of time instants $\left\{t_{0}, t_{1}, \ldots, t_{N}\right\}$ is a partition of $[a, b]$. In the following, the variations of the position error $e$ for the two different implementation methods have been calculated by choosing the partition times $t_{i}$ in (11) as the sampling times.

All the data concerning $e$ are reported in Tables I and II and Fig. 2. From Table I, one observes that the two methods show similar results in terms of average, range, and SD of $e$. However, the implicit controller (5), (10) supersedes the
TABLE I

COMPARISONS OF POSITION ERROR $e$ When $G=10^{5}$.

(a) EXPLICIT CONTROL. (b) IMPLICIT CONTROL

\begin{tabular}{|l|l|l|l|l|}
\hline$h$ & $2 \mathrm{~ms}$ & $5 \mathrm{~ms}$ & $10 \mathrm{~ms}$ & $15 \mathrm{~ms}$ \\
\hline$\langle|e|\rangle$ & 0.98336 & 1.1363 & 2.4372 & 5.5254 \\
\hline $\operatorname{Rge}(e)$ & $(-4.3911$, & $(-4.7722$, & $(-11.364$, & $(-17.767$, \\
& $3.9936)$ & $3.9665)$ & $6.612)$ & $19.018)$ \\
\hline $\mathrm{SD}(e)$ & 1.2430 & 1.3412 & 2.8063 & 6.4330 \\
\hline
\end{tabular}

(a)

\begin{tabular}{|l|l|l|l|l|}
\hline$h$ & $2 \mathrm{~ms}$ & $5 \mathrm{~ms}$ & $10 \mathrm{~ms}$ & $15 \mathrm{~ms}$ \\
\hline$\langle|e|>$ & 0.72598 & 1.7017 & 3.2844 & 5.0835 \\
\hline $\operatorname{Rge}(e)$ & $(-1.8663$, & $(-5.8677$, & $(-8.1843$, & $(-9.2313$, \\
& $2.3094)$ & $4.6001)$ & $6.3261)$ & $8.1833)$ \\
\hline $\mathrm{SD}(e)$ & 0.7941 & 1.9237 & 3.5816 & 5.4152 \\
\hline
\end{tabular}

(b)

TABLE II

VARIATION OF POSITION ERROR $e$ WhEN $G=10^{5}$ (ALso When $G=10^{4}$ )

\begin{tabular}{|l|l|l|l|l|}
\hline$h$ & $2 \mathrm{~ms}$ & $5 \mathrm{~ms}$ & $10 \mathrm{~ms}$ & $15 \mathrm{~ms}$ \\
\hline Explicit & $2.57 \mathrm{e}+3$ & $1.77 \mathrm{e}+03$ & $1.60 \mathrm{e}+03$ & $2.50 \mathrm{e}+03$ \\
control & $(1.78 \mathrm{e}+3)$ & $(904)$ & $(844)$ & $(1.44 \mathrm{e}+3)$ \\
\hline Implicit & $1.63 \mathrm{e}+03$ & 650.27 & 480.16 & 228.80 \\
control & $(1.64 \mathrm{e}+3)$ & $(657)$ & $(428)$ & $(196)$ \\
\hline
\end{tabular}

explicit one in terms of the variation (Table II). The chattering reduction is also visible in Fig. 2, both for $h=15$ and $5 \mathrm{~ms}$. As expected, the oscillations in the explicit case have a magnitude that decreases as $h$ decreases and a frequency that increases as $h$ decreases. The data in Table II show that augmenting $G$ from $10^{4}$ to $10^{5}$ produces no additional output chattering for the implicit controller, while the output chattering increases for the explicit input.

A first conclusion that will be strengthened in the next paragraph is that the implicit control method allows one to take larger gains without decreasing the performance (it means that it is possible to reject/counteract larger perturbations/uncertainties without generating chattering).

\section{B. Comparison of Control Inputs $u$ (5) and $v$ (8), (10)}

The features of the control inputs is a key point in this brief, given that one of the objectives is to show the influence of implicit control to the chattering effect. Let us now pass to the control inputs comparisons, with the data reported in Tables III-V and Fig. 3. The data given in Table III characterize the switching functions for these two methods. It includes the range and variation. In Tables III(b) and IV(b), the data have to be compared inside a single column, but not from one column to another one.

What we call the switching functions are $\operatorname{sgn}\left(\sigma_{k}\right)$ in (8) and $\operatorname{sgn}\left(\sigma_{k+1}\right)$ in (10). This is not to be confused with the discontinuous control $v$ in (7).

Comparisons of the inputs in two methods are given in Table IV from two aspects, that is, range and variation. In addition, the two controllers are shown in Fig. 3.

Globally, the experimental results show that the implicit method drastically reduces the input chattering and magnitude compared with the other two methods. The explicit 


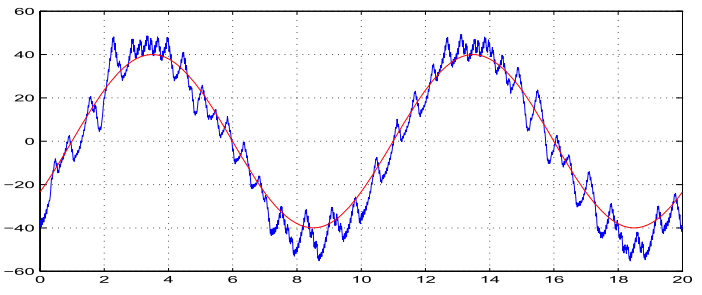

(a)

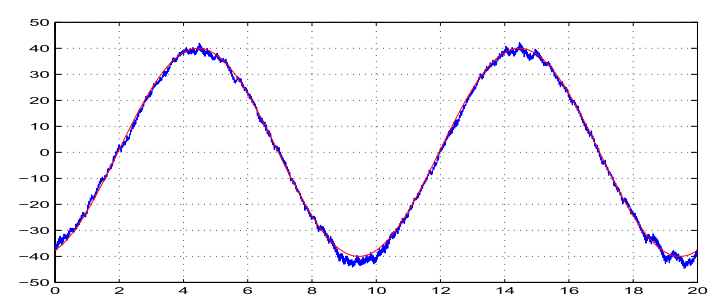

(b)

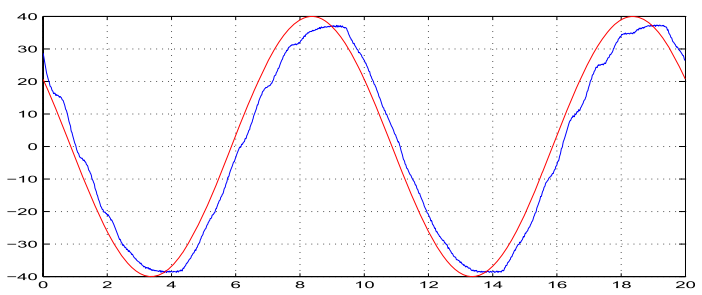

(c)

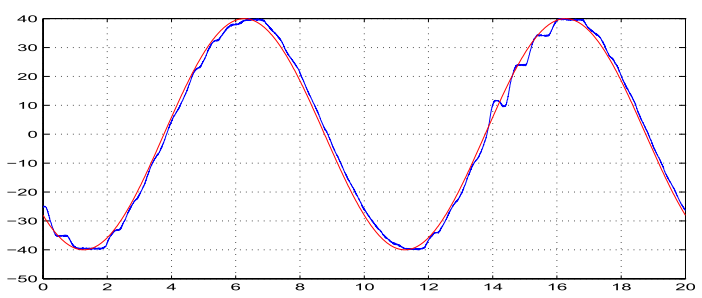

(d)

Fig. 2. Real positions $y$ (in millimeters) in blue and $y_{d}$ (in millimeters) in red, and $h=5$ and $h=15 \mathrm{~ms}$ for $G=10^{5}$. (a) Explicit method where $h=15$ ms. (b) Explicit method where $h=5 \mathrm{~ms}$. (c) Implicit method where $h=15 \mathrm{~ms}$. (d) Implicit method where $h=5 \mathrm{~ms}$.

TABLE III

SWitching FunCtion, GAIN $G=10^{5}$.

(a) RANGE. (b) VARIATION

\begin{tabular}{|l|l|l|l|l|}
\hline$h$ & $2 \mathrm{~ms}$ & $5 \mathrm{~ms}$ & $10 \mathrm{~ms}$ & $15 \mathrm{~ms}$ \\
\hline Explicit & $(-1.000$, & $(-1.000$, & $(-1.000$, & $(-1.000$, \\
control & $1.000)$ & $1.000)$ & $1.000)$ & $1.000)$ \\
\hline Implicit & $(-0.0606$, & $(-0.0360$, & $(-0.0289$, & $(-0.0173$, \\
control & $0.0545)$ & $0.0417)$ & $0.0349)$ & $0.0247)$ \\
\hline
\end{tabular}

(a)

\begin{tabular}{|l|l|l|l|l|}
\hline$h$ & $2 \mathrm{~ms}$ & $5 \mathrm{~ms}$ & $10 \mathrm{~ms}$ & $15 \mathrm{~ms}$ \\
\hline $\begin{array}{l}\text { Explicit } \\
\text { control }\end{array}$ & 2980 & 2050 & 1932 & 1836 \\
\hline $\begin{array}{l}\text { Implicit } \\
\text { control }\end{array}$ & 183.1965 & 34.7510 & 25.2005 & 8.1039 \\
\hline
\end{tabular}

(b)

switching input keeps oscillating between the maximum and minimum values like a bang-bang controller [see the data in Table III(a)]. This results in a large amplitude of inputs $u$ as well [ Table IV(a) and Fig. 3]. In the tables, all the values used
TABLE IV

COMPARISONS OF $u$ WHEN $G=10^{5}$. (a) RANGE OF $u$.

(b) VARIATION OF $u$

\begin{tabular}{|l|l|l|l|l|}
\hline$h$ & $2 \mathrm{~ms}$ & $5 \mathrm{~ms}$ & $10 \mathrm{~ms}$ & $15 \mathrm{~ms}$ \\
\hline $\begin{array}{l}\text { Explicit } \\
\text { control }\end{array}$ & $(-1010)$ & $(-1010)$ & $(-1010)$ & $(-1010)$ \\
\hline $\begin{array}{l}\text { Implicit } \\
\text { control }\end{array}$ & $\begin{array}{l}(-3.2541 \\
3.8092)\end{array}$ & $\begin{array}{l}(-2.0772 \\
2.6066)\end{array}$ & $\begin{array}{l}(-2.0325 \\
2.3656)\end{array}$ & $\begin{array}{l}(-1.9642 \\
1.9461)\end{array}$ \\
\hline
\end{tabular}

(a)

\begin{tabular}{|l|l|l|l|l|}
\hline$h$ & $2 \mathrm{~ms}$ & $5 \mathrm{~ms}$ & $10 \mathrm{~ms}$ & $15 \mathrm{~ms}$ \\
\hline $\begin{array}{l}\text { Explicit } \\
\text { control }\end{array}$ & 29800 & 20500 & 19320 & 18360 \\
\hline $\begin{array}{l}\text { Implicit } \\
\text { control }\end{array}$ & $9.3245 \mathrm{e}+03$ & $1.5389 \mathrm{e}+03$ & $1.1560 \mathrm{e}+03$ & 629.0904 \\
\hline
\end{tabular}

(b)

TABLE V

Magnitude of Implicit S Witching Function $\operatorname{sgn}\left(x_{k+1}\right)$ FOR VARYING GAINS $G$ AND SAMPLING PERIOD $h$

\begin{tabular}{|l|l|l|l|}
\hline$G$ & $10^{4}$ & $10^{5}$ & $10^{6}$ \\
\hline $5 \mathrm{~ms}$ & $(-0.3,0.35)$ & $(-0.03,0.035)$ & $(-0.003,0.003)$ \\
\hline $10 \mathrm{~ms}$ & $(-0.25,0.3)$ & $(-0.025,0.03)$ & $(-0.0025,0.0025)$ \\
\hline
\end{tabular}

to characterize the chattering in implicit method are invariably much less than the other two methods. The magnitude of the ranges of the switching function and control $u$ in the implicit method is much less than the other two methods [Table IV(a)]. These facts are well supported by Fig. 3. Consider Fig. 3 when $h=15 \mathrm{~ms}$, while the ranges of the control law $u$ in explicit method are between -10 and 10 [Fig. 3(b)], the range of $u$ for the implicit case is strictly between -2 and 2 [Fig. 3(d)]. This is also true when $h=5 \mathrm{~ms}$ [Fig. 3(a) and (c)]. The magnitudes of the switching function for the implicit controller, for three different gains $G$ and two different sampling periods $h$, are reported in Table V. It confirms that the magnitude of the input $v_{k}$ in (10), which is the switching function times the gain $G$, does not depend neither on $G$ nor on $h$ in this range of sampling times.

This insensitivity property is believed to be a fundamental property of the implicit method introduced in [1] and [2], compared with explicit implementations that drastically differ when $h$ and/or $G$ are varied.

The results shown in Fig. 3 clearly demonstrate that whereas the explicit controller tends to approximate a signal that switches infinitely fast between two extreme values like bang-bang inputs, this is not at all the case for the implicit controller that behaves in a totally different way. This is a nice confirmation of both theoretical and numerical predictions [1], [2] that the implicit controller does represent the discrete-time approximation of the selection of the differential inclusion according to Filippov's mathematical framework.

Input chattering is also reported in Tables III(b) and IV(b). The variation of the implicit switching function is much smaller than the variation of the explicit one, and this is the same for the variation of $u$. These results demonstrate that the switching function chattering and magnitude strongly influence the input $u$ in (5). 


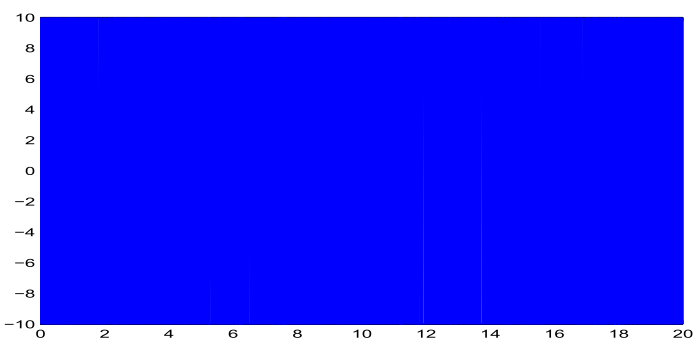

(a)

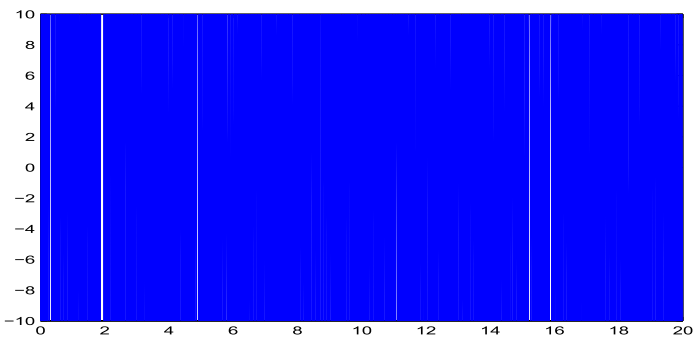

(b)

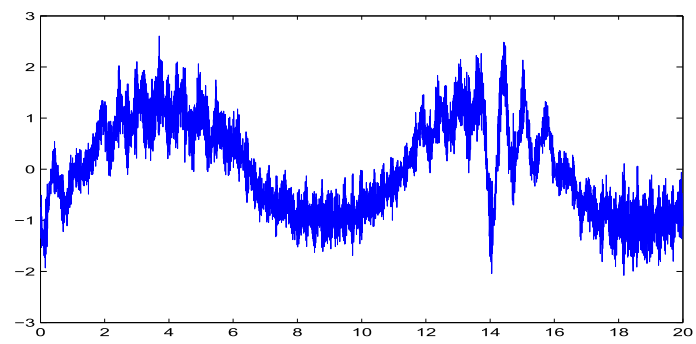

(c)

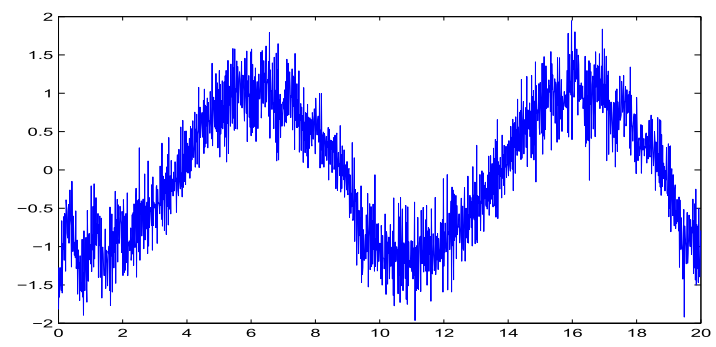

(d)

Fig. 3. Comparison of the control $u$ between explicit method, saturation method, and implicit method. (a) Explicit method where $G=10^{5}$ and $h=5 \mathrm{~ms}$. (b) Explicit method where $G=10^{5}$ and $h=15 \mathrm{~ms}$. (c) Implicit method where $G=10^{5}$ and $h=5 \mathrm{~ms}$. (d) Implicit method where $G=10^{5}$ and $h=15 \mathrm{~ms}$.

\section{CONCLUSION}

Experiments have been conducted on an electropneumatic system, with two different discrete-time implementations of the equivalent-control-based sliding mode controller: explicit and implicit discretizations (the data with a saturated explicit input may be found in [17]). The results demonstrate that the theoretical and numerical predictions of [1] and [2] are true: the implicit implementation, which consists merely of a projection on the interval $[-1,1]$ and is thus very easy to implement in a code, drastically supersedes the explicit one. The output and input chattering are reduced in a significant way, without changing the controller basic structure (i.e., no additional filter, observer, or dynamic controller is added compared with the original basic sliding mode controller) and keeping its simplicity (in particular, the gain tuning is easy, which is a strong feature of the Equivalent-Control-Based-Sliding-ModeControl method). The proposed implicit discretization method is generic in the sense that it could apply to any kind of sliding mode set-valued control. The same conclusions have been drawn in [8] with the twisting controller.

\section{REFERENCES}

[1] V. Acary and B. Brogliato, "Implicit Euler numerical scheme and chattering-free implementation of sliding mode systems," Syst. Control Lett., vol. 59, no. 5, pp. 284-293, 2010.

[2] V. Acary, B. Brogliato, and Y. V. Orlov, "Chattering-free digital slidingmode control with state observer and disturbance rejection," IEEE Trans. Autom. Control, vol. 57, no. 5, pp. 1087-1101, May 2012.

[3] A. Bartoszewicz, "Discrete-time quasi-sliding-mode control strategies," IEEE Trans. Ind. Electron., vol. 45, no. 4, pp. 633-637, Aug. 1998.

[4] R. Castro-Linarès, S. Laghrouche, A. Glumineau, and F. Plestan, "Higher order sliding mode observer-based control," in Proc. IFAC Symp. Syst., Struct. Control, Oaxaca, Mexico, 2004, pp. 481-486.

[5] Z. Galias and X. Yu, "Complex discretization behaviors of a simple sliding-mode control system," IEEE Trans. Circuits Syst. II, Exp. Briefs, vol. 53, no. 8, pp. 652-656, Aug. 2006.

[6] Z. Galias and X. Yu, "Analysis of zero-order holder discretization of two-dimensional sliding-mode control systems," IEEE Trans. Circuits Syst. II, Exp. Briefs, vol. 55, no. 12, pp. 1269-1273, Dec. 2008.

[7] A. Girin, F. Plestan, X. Brun, and A. Glumineau, "High-order slidingmode controllers of an electropneumatic actuator: Application to an aeronautic benchmark," IEEE Trans. Control Syst. Technol., vol. 17, no. 3, pp. 633-645, May 2009.

[8] O. Huber, V. Acary, B. Brogliato, and F. Plestan, "Discrete-time twisting controller without numerical chattering: Analysis and experimental results with an implicit method," in Proc. IEEE Conf. Decision Control, Los Angeles, CA, USA, Dec. 2014.

[9] S. Laghrouche, M. Smaoui, F. Plestan, and X. Brun, "Higher order sliding mode control based on optimal approach of an electropneumatic actuator," Int. J. Control, vol. 79, no. 2, pp. 119-131, 2006.

[10] Y. Orlov, Discontinuous Systems. London, U.K.: Springer-Verlag, 2009.

[11] S. Sesmat and S. Scavarda, "Static characteristics of a three way servovalve," in Proc. Conf. Fluid Power Technol., Aachen, Germany, vol. 2. 1996, pp. 643-652.

[12] Y. Shtessel, M. Taleb, and F. Plestan, "A novel adaptive-gain supertwisting sliding mode controller: Methodology and application," Automatica, vol. 48, no. 5, pp. 759-769, 2012.

[13] H. Sira-Ramirez, "Non-linear discrete variable structure systems in quasi-sliding mode," Int. J. Control, vol. 54, no. 5, pp. 1171-1187, 1991.

[14] V. I. Utkin, Sliding Modes in Control and Optimization. Berlin, Germany: Springer-Verlag, 1992.

[15] V. Utkin, J. Guldner, and J. Shi, Sliding Mode Control in ElectroMechanical Systems (Automation and Control Engineering), 2nd ed. Boca Raton, FL, USA: CRC Press, 2009.

[16] B. Wang, X. Yu, and G. Chen, "ZOH discretization effect on single-input sliding mode control systems with matched uncertainties," Automatica, vol. 45, no. 1, pp. 118-125, 2009.

[17] B. Wang, B. Brogliato, V. Acary, A. Boubakir, and F. Plestan. "Comparisons between implicit and explicit discrete-time implementations of equivalent-control-based sliding mode controllers: Input and output chattering suppression via the implicit method," INRIA, Grenoble, France, Res. Rep. [Online]. Available: https://hal.inria.fr/hal01087400/document, accessed Nov. 26, 2014. 